\title{
A propósito del inspector general de la Policía Nacional Civil
}

\begin{abstract}
¿No hay gente capaz entre los más de cinco millones de salvadoreñas y salvadoreños que, según el censo oficial, habitan el territorio nacional o entre quienes, superando el millon, residen fuera del país? ¿Es por falta de olfato para ubicarla, porque se ignora la importancia que en este momento representa encontrarla o porque no existe voluntad para hacerlo? Sea como sea, en la actualidad nos enfrentamos a un serio problema: desde el inicio de su labor, las dos instituciones estatales surgidas de los acuerdos de paz y relacionadas directamente con la defensa, protección y promoción de los derechos humanos en El Salvador no siempre han contado con los servicios de las personas idóneas en algunos de sus puestos claves para iniciar así su trabajo de manera eficaz, consolidar su presencia y contribuir a generar confianza entre la población.
\end{abstract}

Con el ánimo de responder a las anteriores interrogantes o para terminar planteándonos otras más, se deben analizar aspectos concretos del problema, sobre todo en lo que se refiere a los actuales procesos de selección para acceder a ciertos cargos. Ya comentamos antes la reciente elección de la Procuradora para la Defensa de los Derechos Humanos (ECA, 1995, 557). Ahora toca el turno a lo que está sucediendo dentro de la Policía Nacional Civil.

Desde que ésta empezó a desplegarse por el territorio nacional, comenzamos a tener conocimiento de una serie de actos cometidos por sus miembros en detrimento de la imagen institucional con la que fue concebida: una policía respetuosa de los derechos humanos. Con el paso del tiempo, tales actos se fueron haciendo cada vez más numerosos. Eso no quiere decir que durante su corta vida no existan cosas positivas que deben y merecen ser reconocidas; sin embargo, a estas alturas, tras la desaparición de la Misión de Observadores de Naciones Unidas en El Salvador (ONUSAL), consideramos prioritario señalar lo que -más temprano que tarde - puede convertirse en una enfermedad muy grave, similar a la que en los antiguos cuerpos de seguridad sólo se pudo curar con su desaparición. $Y$ es que, por mucho que algunos pretendan cerrar los ojos, en la nueva policía - nacida del dolor, el heroísmo y el sacrificio de nuestro pueblo- ya empezaron a aparecer vicios propios de los otganismos que la antecedieron: represión, uso indebido de la fuerza, actuaciones arbitrarias alejadas de la ley y encubrimiento, entre otras cosas.

Es un hecho que dentro del cuerpo de seguridad hay individuos quienes, desde los importantes cargos que ocupan, han realizado o permitido que se realicen actos que lo deslegitiman y le impiden - de esa manera- cumplir fielmente con su obligación de proteger y garantizar el libre ejercicio 
de los derechos y las libertades de las personas, tal como lo señala el primer artículo de su ley orgánica. A ello se debe que, al igual que en documentos anteriores, la división de derechos humanos de ONUSAL haya señalado en su doceavo informe la responsabilidad de la policía en hechos contrarios a la dignidad humana. Así, de julio a septiembre de 1994 se sabe que ésta admitio 87 denuncias contra agentes de la nueva policía; dichos casos constituyeron el 37.8 por ciento del total de las quejas aceptadas. En su siguiente informe, la división de ONUSAL ubicó las deficiencias básicas de la policía, algunas de las cuales las agrupó en los siguientes rubros: falta de capacidad para investigar el delito, escasa coordinación institucional y manejo inadecuado de situaciones críticas.

Sobre lo primero — su incapacidad para realizar indagaciones adecuadas - encontramos que durante el período examinado por ONUSAL en el treceavo informe (de octubre de 1994 a marzo de 1995) sólo el 15 por ciento de las unidades de despliegue territorial salieron de sus locales a realizar tareas de investigación, mientras que el 75 por ciento efectuó algunas diligencias dentro de las instalaciones de la policía, sin salir al terreno. Para colmo de males y estando desprovista de los medios suficientes para impulsar su labor, la policía se limitó a iniciar averiguaciones en el 22 por ciento de los casos que conocío.

Del reducido porcentaje de unidades que trabajaron en el terreno y considerando los pocos casos atendidos, no se podía esperar resultados positivos, pues las actuaciones no fueron ni abundantes ni buenas; casi siempre, los agentes se conformaron con levantar el acta de inspección y tomar declaraciones - tanto de la persona ofendida como de los testigos, cuando los hubo- sin llevar a cabo verdaderas investigaciones. En esos seis meses, no hicieron relato de los hechos. Para llenar este vacío, los policías utilizaron la declaración extrajudicial del ofendido. En ocasiones, los agentes calificaron jurídicamente las conductas sin aportar elementos de juicio. En las remisiones al juez por faltas penales, esta situación se repitió constantemente. ONUSAL sostiene, además, que la Policía Nacional Civil no tenía entre sus prioridades combatir los crímenes graves.
En teorfa, para realizar este tipo de trabajo especializado, la Policía Nacional Civil cuenta con la División de Investigación Criminal (DIC). Sin embargo, que ésta exista no quiere decir que las cosas marchen bien. Dentro de ella se destaca el no funcionamiento de su "unidad especializada en la investigación de delitos políticamente motivados", cuya creación recomèndó el Grupo Conjunto, el cual examinó el fenómeno de los "escuadrones de la muerte". Por eso no se avanzó ni en los casos enviados por dicho Grupo ni en otros posteriores, especialmente en el de David Fausto Merino, dirigente del FMLN conocido como "Franco". En este caso, la unidad mostró —n palabras de ONUSAL- "una ineficiencia casi inexplicable". Esta gran cantidad de limitaciones en materia investigativa, según el informe, "repercuten negativamente en los procesos judiciales, al carecer los tribunales y la Fiscalía de los elementos de prueba necesarios para actuar, todo lo cual redunda en la permanencia de la impunidad". Con esta conclusión de los observadores internacionales y con la gravedad de sus consecuencias para el presente y el futuro del país, estamos de acuerdo.

Y qué decir de la limitada coordinación entre las instituciones relacionadas con la seguridad pública, también señalada por los observadores internacionales. ONUSAl dijo que ya se habían dado algunos pasos positivos por parte de la Policía Nacional Civil y la Procuraduría para la Defensa de los Derechos Humanos en esta línea. Sin embargo, es mucho lo que falta por hacer para que el Organo Judicial, la Fiscalía General de la República y el servicio de defensoría de la Procuraduría General de la República participen activamente. Como estaban las cosas al finalizar el treceavo informe de ONUSAL, el cuadro no era alentador: al examinar 49 unidades de la Policía Nacional Civil, en febrero y marzo, se verificó que éstas sólo notificaron al juez competente el 12 por ciento de las actuaciones que iniciaron durante una semana. Con la Fiscalía no hubo comunicación.

Además, de todas las órdenes de captura giradas por los tribunales, la policía sólo hizo efectivas el 20 por ciento, lo cual representa el 11 por ciento del total de las detenciones realizadas. El resto de las capturas se efectuó en flagrancia (66 
por ciento) y en flagrancia impropia (23 por ciento). Finalmente, el estudio reveló algunas de los errores que aparecen en el registro de las actuaciones y diligencias policiales. Esto, dice el informe, "repercute en la elaboración de la documentación que se remite a las autoridades judiciales", dentro de la cual "se omite el cumplimiento de requisitos legales, lo que puede derivar en la declaración de nulidades procesales".

Las otras insuficiencias fundamentales señaladas por ONUSAL se refieren a las conductas policiales inadecuadas para enfrentar manifestaciones públicas y situaciones críticas, que durante los seis meses estudiados dejaron una víctima mortal al menos y numerosos lesionados. Cabe citar, como ejemplos, los siguientes casos: la de los trabajadores del Instituto Salvadoreño del Seguro Social (ISSS), en diciembre de 1994; la de las protestas masivas de la Asociación de Desmovilizados de la Fuerza Armada (ADEFAES), en enero del año en curso y la de la Asociación de Lisiados de la Fuerza Armada (ALFAES) y la Asociación Salvadoreña de Lisiados y Discapacitados de Guerra (ASALDIG), el 29 de marzo. Carencia de recursos, preparación insuficiente, desorganización operativa, lentitud e indecisión, y desproporción en su actuación son algunas de las graves limitaciones que se señalan en el informe.

Uno de los principales factores para que ahora estemos preocupados por el cuadro que nos ofrece ONUSAL y por lo que constatamos con nuestra labor es, sin duda, la falta de un funcionamiento eficaz de los controles internos y externos a los cuales corresponde fiscalizar las actividades de sus integrantes. De los externos destacan tres: el Organo Legislativo, la Procuraduría para la Defensa de los Derechos Humanos y las diversas expresiones de la sociedad civil preocupadas por el tema. Los internos, contemplados dentro de la legislación policial correspondiente, están constituidos por la unidad de control, la unidad de investigaciones disciplinarias y el tribunal disciplinario. En teoría, este conjunto de mecanismos serían suficientes para garantizar el funcionamiento aceptable de nuestra policía, según las exigencias de la población y las necesidades de lo que se ha dado en llamar la nueva etapa por la que transita El Salva-

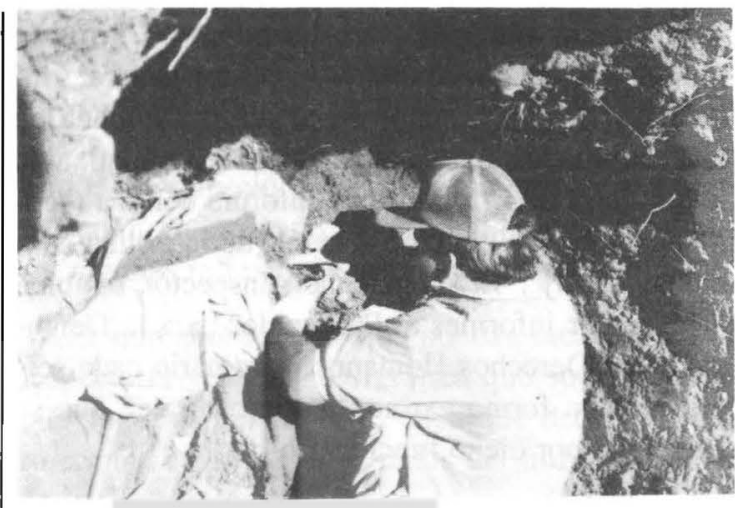

dor. Cabe mencionar, rápidamente, el mandato de cada una de las instancias internas de vigilancia.

Según el Artículo 10 de la ley orgánica de la Policía Nacional Civil, a la unidad de control le corresponde "regular cualquier servicio de policía". La unidad de investigaciones disciplinarias, por su parte, debe "investigar las graves faltas cometidas por los miembros de la policía". Dentro del reglamento disciplinario se abunda más sobre la última de esas dos instancias cuando, en el Articulo 24, Título VI, se establece que "es el organismo encargado de llevar a cabo las investigaciones de todas las faltas disciplinarias graves y muy graves". "También", continúa el texto, "tendrá facultades para investigar los casos de faltas leves con reincidencia de dos veces, cometidas por personal policial en el período de doce meses".

El tribunal disciplinario quedó definido en el Artículo 30, sección segunda, Título VI del citado reglamento, como "el organismo competente para resolver en primera instancia de las faltas graves y muy graves cometidas por el personal policial e imponer las sanciones correspondientes, toda vez que no constituyan hecho punible". Pero además de los mecanismos anteriores, existe la inspectoría general, la cual no debe ser considerada como parte de la maquinaria interna para controlar a la Policía Nacional Civil, no obstante aparecer contemplada en el Artículo 8 de la mencionada ley orgánica. Dicho artículo determina que la inspectoría funcionará bajo la autoridad del Viceministro de Seguridad Pública y su misión es "vigilar y controlar las actuaciones de los servicios operativos y de gestión del cuerpo, así como lo referente a los derechos humanos". El que no sea un control ex- 
terno queda aún más claro cuando, en el mismo artículo, se establece que el inspector general "informará al Viceministro de Seguridad Pública de las actividades que realiza de conformidad a la ley, quien transcribirá dicho informe con las recomendaciones al director general [de la Policía Nacional Civil]". El mencionado inspector también debe rendir informes al Procurador para la Defensa de los Derechos Humanos, "ordinario cada seis meses y de forma extraordinaria cada vez que se le solicite por dicho funcionario".

En su doceavo reporte sobre la situación de los derechos humanos en el país, ONUSAL sostuvo que "la actitud de los mandos de las delegaciones, subdelegaciones o puestos donde se originan los hechos luego denunciados, así como de las mismas unidades de control e investigación disciplinaria, no es uniforme". En algunas ocasiones", dice la Misión, "se ha verificado que la respuesta institucional no es clara y contundente; en otras se han detectado alentadores señales de voluntad para llegar al fondo en las investigaciones. Sin embargo, no se observa una tendencia hacia la necesaria rigidez que en esta etapa fundacional de la Policía Nacional Civil deben seguir los procedimientos disciplinarios internos". Por consiguiente, desde entonces - julio a septiembre de 1994 - las cosas no marchaban muy bien.

En su siguiente informe, ONUSAL tampoco pudo emitir un dictamen positivo sobre los mecanismos internos de fiscalización y control de la Policía Nacional Civil. No pudo porque, lastimosamente, éstos seguran sin funcionar. A principios de diciembre, la Fiscalía había iniciado procesos penales contra 71 integrantes del cuerpo; mientras tanto - nótese la diferencia tan grande--, la unidad de investigación disciplinaria de la Policía Nacional Civil tramitaba sanciones administrativas en sólo 8 de esos casos. También en esos días, dicha unidad tenía en su poder 506 casos de los cuales 430 estaban pendientes de investigación. Como muestra de su lento caminar en relación a los acontecimientos y las demandas de la realidad, en el mes de marzo, esa misma unidad tenía ya 780 expedientes, 116 de ellos por faltas graves y muy graves: la proporción habra crecido casi en un 55 por ciento, sin que se avanzase mucho en las investigaciones. Las autoridades de la Policía Nacional Civil prometieron resolvèr ágilmente los casos graves e impulsar las reformas necesarias para corregir las fallas, pero hasta la fecha no se han visto resultados significativos.

El 2 de marzo, el tribunal disciplinario de la Policía Nacional Civil se dice que estaba diligenciando 26 denuncias, 18 de las cuales ONUSAL consideraba graves. Recordemos los 116 casos en manos de la unidad de investigaciones disciplinarias que se mencionaron antes para, sin malicia, establecer una comparación que no contribuye en nada a levantar el ánimo. Del trabajo desarrollado por quien hasta el 31 de marzo fungió como inspector general, sólo queda citar textualmente el informe de ONUSAL, "careció de claridad acerca de sus facultades, lo que se tradujo en una notoria ineficacia de su trabajo".

Con ese lento y deficiente funcionamiento de los mecanismos creados dentro de la misma Policía Nacional Civil para verificar el desempeño de sus miembros y, en su caso, sancionarlos, era lógico esperar que durante los meses que abarcó el último informe de ONUSAL la nueva policía continuara incurriendo en graves violaciones de los derechos humanos. Y así fue. Los observadores internacionales calificaron esos hechos como "algunos casos aislados de graves violaciones al derecho a la vida y a la integridad física por parte de efectivos de la Policía Nacional Civil". No obstante, afirmaron que fue "inquietante verificar un cambio negativo en la entidad de estas violaciones, bien en razón de la gravedad de sus características, del rango de los efectivos en ellas involucrados, o de la existencia de conductas de algunos miembros de la Policía Nacional Civil destinadas a desviar o entorpecer las investigaciones".

Entre los casos que aparecen como ejemplo en el informe y que obviamente no son todos los que ocurrieron durante el semestre, encontramos ejecuciones y detenciones arbitrarias, malos tratos, tortura y uso excesivo de la fuerza. De uno de ellos, damos cuenta en seguida. Nelson Arnulfo Pineda Sosa era un menor de edad que, el 4 de noviembre de 1994, conducía un vehículo acompañado por un amigo en la ciudad de San Miguel. 


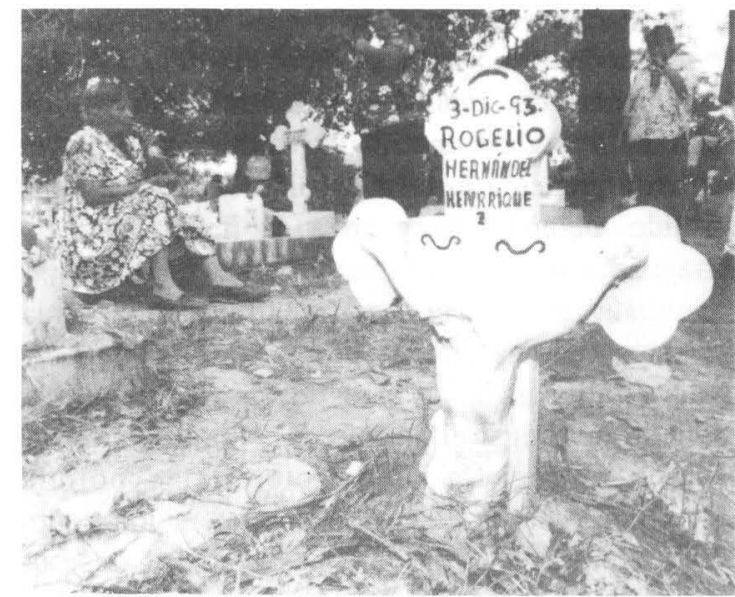

Dos agentes de la Policía Nacional Civil quisieron detener a los jóvenes, pero éstos intentaron huir y en la persecución fueron atacados a balazos. En ese instante falleció Pineda Sosa. Para justificar lo injustificable, los policías dijeron que el conductor del vehículo portaba una granada de mano y -para hacer más creíble su versión- la colocaron dentro del vehículo de la víctima. La granada con la que trataron de encubrir su grave e irreparable falta, según se estableció posteriormente, estaba en calidad de depósito en la delegación de la Policía Nacional Civil desde el 17 de septiembre. De ello tuvo conocimiento el mismo director general de la nueva institución. Pese a eso, al menos hasta el momento de la publicación del informe de ONUSAL y según se dice en el mismo, "inexplicablemente la Cámara de lo Penal de la primera sección de oriente decretó la libertad del sargento que estaba al mando de esa patrulla".

Con todo lo anterior, sin duda, el presente de esa nueva policía que con justa razón generó esperanzas en muchos, se está pareciendo más a los cuerpos del pasado que al diseño teórico que empezó a surgir con los acuerdos de paz, que se plasmó en la Constitución y que fue tomando mayor cuerpo con la aprobación de la legislación secundaria sobre la materia. Pero también, sin duda, el futuro inmediato de esa nueva policía dependerá de la actuación, atinada o no, del conjunto de mecanismos internos y externos encargados de controlar su actuación y sancionar a sus integrantes cuando incurran en faltas. A propósito de lo anterior y en relacion al motivo central de este comen- tario, durante todo el mes de abril y buena parte de mayo, al menos hasta el momento de escribir estas líneas, ha estado sobre el tapete la discusión en torno a la selección de la persona que deberá ocupar el cargo de inspector general. Cabe, pues, hacer algunas reflexiones sobre ese tema.

El que ahora centremos nuestra atención en la inspectoría general no significa que sobre los demás mecanismos no haya nada qué decir. Ya nos referimos antes a ciertos datos del último informe de la división de derechos humanos de ONUSAL. Cabe agregar que en dicho informe, al hablar sobre las deficiencias de la unidad de investigación disciplinaria, se propuso que algunas de las soluciones a éstas "deberían apuntar a la incorporación a esa unidad de personal de dirección debidamente capacitado para el desempeño de las funciones que le son propias", lo que indica que no andamos tan errados: el buen funcionamiento de estas instancias, fundamentales para el mejor desenvolvimiento de la policía en materia de derechos humanos, depende mucho del personal que se encuentre ocupando determinados cargos. En general, el desempeño de todos los mecanismos disciplinarios internos fue calificado por el secretario general de $\mathrm{Na}$ ciones Unidas, en el último informe que envió al Consejo de Seguridad sobre ONUSAL, como "ineficaz por falta de claridad respecto de sus funciones de supervisión".

Regresando al tema del inspector general, cabe decir que éste ha cobrado notoriedad tras el repentino anuncio de la destitución de Eulogio de Jesús Guerra Payés, quien fungió como tal desde el 26 de septiembre de 1994 hasta el 31 de marzo. Seis meses y cinco días bastaron para que las autoridades gubernamentales encargadas de la seguridad pública se dieran cuenta que no era la persona adecuada para el cargo. A varias organizaciones de la sociedad civil que damos seguimiento a la situación de los derechos humanos en el país desde hace varios años y que, quieran o no, conocemos el medio y a quienes se mueven dentro de él, nunca aprobamos el nombramiento del Viceministro de Seguridad Pública y desde el principio advertimos públicamente que se cometía un error.

Objetivamente hay que reconocer que el traba- 
jo de Guerra Payés, desde el inicio, estaba condenado al fracaso por varias razones. Una de ellas era el grave retraso en su nombramiento. Si éste se hubiese hecho desde el momento mismo en que se estableció la Policía Nacional Civil, cuando sus miembros eran menos y las dificultades menores, se hubiesen establecido precedentes disciplinarios positivos para regular la conducta de sus integrantes actuales y crear en ellos hábitos de respeto de los derechos humanos.

En el mismo sentido, y aunque aparentemente no es responsabilidad suya, el ex inspector llegó al cargo pese a los cuestionamientos que se hicieron sobre su capacidad e idoneidad. Fueron diversas organizaciones las que, con conocimiento de causa, se opusieron a que Guerra Payés accediera a tan importante y delicado puesto. Las organizaciones no gubernamentales de derechos humanos, conociendo el desempeño de Guerra Payés en la comisión gubernamental de derechos humanos durante varios años, incluidos los del conflicto, comunicaron su disconformidad al entonces Procurador para la Defensa de los Derechos Humanos, Carlos Molina Fonseca, quien, en otra muestra de su desatinada actuación, no atendio dichas opiniones y avalo la designación.

Finalmente, entre las razones para el descalabro del ahora ex funcionario encargado "de vigilar y controlar las actuaciones de los servicios operativos y de gestión de cuerpo, así como lo referente a los derechos humanos", también se encuentra el poco apoyo que recibió de sus superiores. Sin embargo, pese a esos inconvenientes, Guerra Payés debió haber actuado y hecho todos los esfuerzos posibles para darle cabal cumplimiento a su mandato. Nos consta que desde el inicio de su gestión, algunas instituciones dentro y fuera del pars -estuvieran o no de acuerdo con su nombramiento- le comunicaron su disposición a colaborar. Lamentablemente, todo quedó a nivel de pláticas formales, de las cuales no se siguió ninguna acción concreta por parte Guerra Payés.

Así, a finales de marzo, tras más de medio año desperdiciado, se produjo la destitución. No sabemos si son ciertas las declaraciones del ex inspector general cuando afirmó que existían problemas de corrupción dentro del cuerpo, aunque no nos extrañaría que así fuera. Las pruebas de ello, según se dice, las tiene la Corte de Cuentas, que realizó una auditoría en el cuerpo policial a raíz de una incitativa de Guerra Payés, quien argumenta que su despido se debe a haber pedido tal auditoría y no a su incapacidad. Se asegura que entre dichas pruebas se incluyen anomalías relacionadas con contratos de arrendamiento, mejoras en construcciones y compra de computadoras. El ex inspector sostiene que solicitó investigar el destino de 50 mil dólares que fueron entregados al director de la policía, Rodrigo Avila, producto de una operación contra el narcotráfico. Avila negó la veracidad de estas denuncias, alegando que "en toda institución existen pequeños fallos de administración. Por ejemplo: una licitación mal elegida por la urgencia del caso u otras cosas pequeñas". Por su parte, el Viceministro de Seguridad Pública, Hugo Barrera, argumentó que las violaciones de los derechos humanos dentro de la Policía Nacional Civil no son ningún secreto y señaló la incompetencia como causa del retiro de Guerra Payés.

Ante ese cuadro, a nosotros nos surgen algunas interrogantes. ¿Será cierto que no existen actos de corrupción en el interior de la Policía Nacional Civil cuando el mismo director los admite, aunque los llame "fallos de administración" y diga que son "pequeños"? ¿Se puede permitir, entonces, que existan "corrupcioncitas" en un cuerpo que - por ser parte de sus funciones más importantes-- debe prevenir y combatir toda clase de delitos? ¿Será difícil pensar que la Policía Nacional Civil es responsable de violaciones de los derechos humanos y que éstas no se ocultan, tras haber visto la saña y la desproporción con que se actuó para dispersar a personas vulnerables como son las y los lisiados, sin que sus autoridades reconozcan aunque sea mínimamente que fallaron? Si así proceden frente a las cámaras de televisión, ¿cómo se comportarán fuera de éstas?

Mientras se aclaran esas cosas, si es que eso sucede, no dudamos que Guerra Payés desperdició la oportunidad para contribuir a corregir muchos de los males dentro de la institución. Eso corrobora la opinión de diversas organizaciones de derechos humanos que advirtieron con tiempo 
sobre la falta de capacidad del ahora ex inspector general. Mucha de la responsabilidad por ese mal desempeño y por los costos pagados por la población entera, se deben atribuir al anterior Procurador para la Defensa de los Derechos Humanos, quien pudo vetar legalmente esa designación y no lo hizo, pese a las advertencias ya señaladas. Tampoco fue capaz de vigilar su trabajo y denunciar en su debida oportunidad las anomalías del inspector general.

Se dice que la salida de Guerra Payés obedeció a una decisión del presidente Calderón Sol, quien en alguna oportunidad habría dicho, "al funcionario que no rinda y no se esfuerce se le pedirá la renuncia; y si no la interpone, será destituido. La principal obligación de un jefe de Estado es ver que las instituciones caminen y que los funcionarios trabajen". Esa postura nos parece buena, pero podría ser mejor si se aplicara verdaderamente a toda la administración pública y si antes de nombrar a otras personas para sustituir a los ineptos se oyeran y se tomaran en cuenta las opiniones de quienes están en contacto con las problemáticas específicas $\mathrm{y}$, por tanto, tienen capacidad para aportar criterios válidos para la selección de los candidatos idóneas. Para ello es necesario superar los verticalismos, la prepotencia y los tradicionales autoritarismos.

En ese marco se debe inscribir la elección del futuro inspector general de la Policía Nacional Civil. Hasta la fecha, sólo se había mencionado la candidatura de Francisco Bertrand Galindo, quien funge como asesor jurídico del Viceministro de Seguridad Pública. Contradictoriamente, el presidente Calderón Sol, al igual que el viceministro Barrera, hicieron públicas sus simpatías por este jurista. Semejante procedimiento fue incorrecto, puesto que podía entorpecer el desarrollo del proceso de selección contemplado en la legislación y, además, podía tener repercusiones en el ya de por sí inadecuado funcionamiento institucional del país. De acuerdo a lo que señala el Artículo 8 de la ley orgánica de la Policía Nacional Civil, el inspector general será nombrado por el Ministro del Interior y Seguridad Pública, previa aprobación de la Procuradora para la Defensa de los Derechos Humanos y del Fiscal

\section{General.}

Y es que en un país donde el sistema político continúa caracterizándose por un fuerte componente presidencialista, las posturas del primer mandatario influyen enormemente en el resto de los funcionarios de la administración pública. Al menos en la mayoría de los casos así sucede, limitando la autonomía de los servidores públicos de menor jerarquía, quienes, en teoría, deberían actuar basándose únicamente en el mandato que la ley establece. Dado que en este caso dos importantes funcionarios del Ministerio Público debían dar su aprobación al candidato presentado, las manifestaciones de apoyo anticipadas resultaron imprudentes. Más conveniente sería, tal como se encuentran las cosas ahora, que el presidente, los ministros y los funcionarios en general se abstuvieran de manifestar públicamente sus preferencias, pues, quiérase o no, esta clase de intervenciones condiciona la decisión de quienes deben dar su aval para proceder a hacer el nombramiento del inspector general de la Policía Nacional Civil.

El Fiscal General no sorprendió a nadie y, sin violentar la tradición, aprobó sin cuestionar o pedir sugerencia alguna lo que según él debía aprobar: la decisión de arriba. En cambio, la recién electa Procuradora para la Defensa de los Derechos Humanos se opuso al nombramiento y desconcerto $-\mathrm{y}$ seguramente hasta molestó- a quienes creyeron que en este país "se cambiaron muchas cosas para no cambiar nada". La procuradora Victoria Marina de Avilés desde el principio mostró un mejor criterio que el primer mandatario y que el Viceministro de Seguridad Pública al manifestar que le habían presentado como candidato para inspector general de la Policía Nacional Civil a Bertrand Galindo. Pero agregó que se debían considerar otros nombres para poder tomar una decisión mejor. En concreto, propuso que le presentaran una terna. En su opinión, el nombramiento era demasiado importante para reducirlo a un nombre, por lo tanto, pidió "un procedimiento en el que se juegue con varios nombres".

Al no ser escuchada y tras esperar un tiempo prudencial, Avilés envió una carta al Ministro del 
Interior el 26 de abril, expresando, entre otras cosas, que "luego de valorar la candidatura propuesta en función de los criterios antes referidos, ésta no aparece, a juicio de la procuradora, como la más idónea desde la perspectiva estricta de las competencias que en materia de derechos humanos la ley establece". Dichos criterios, según la carta, tienen que ver con "los antecedentes y la idoneidad de los candidatos respecto del conocimiento, versación y autoridad en materia de derechos humanos, así como su autonomía de conciencia para poder ejercer las funciones contraloras y de investigación en torno a eventuales violaciones con responsabilidad de los agentes de la Policía Nacional Civil en ejercicio de sus funciones".

Considerando sobre todo este último criterio, fundamental para el adecuado desenvolvimiento del inspector general, cabe decir que Bertrand Galindo, por ser en la actualidad un buen asesor jurídico del Viceministro de Seguridad Pública, en palabras de este funcionario, posiblemente no era la persona adecuada para el cargo. Lo mejor, y a ello contribuyó Avilés con su veto, era que ese "buen asesor jurídico" siguiera en su cargo y se buscara como "buen inspector general" a otra persona sin ninguna relación previa, directa o indirecta, con la policía. Pero, además, Avilés no dejó de reiterar en su carta su preocupación, planteada por la opinión pública, "en el sentido que al no establecer la ley procedimientos específicos para la nominación del inspector general, sería muy razonable y adecuado la presentación de una terna que posibilite una ponderación comparada de los atributos y calidades de los profesionales que el ejecutivo tenga a bien proponer en uso de sus facultades para desempeñar tan importante cargo".

La Procuradora tiene toda la razón al pedir una terna para escoger al candidato que debe ocupar el cargo de inspector general. Además de esto, es importante modificar el Artículo 8 de la ley orgánica de la Policía Nacional Civil para contemplar, entre otras cosas, la participación de la Procuraduría para la Defensa de los Derechos Humanos y la Fiscalía General de la República cuando, por algún motivo, sea requiera reemplazar a la persona que ocupa el cargo de inspector gene- ral de la policía. Por consiguiente, las razones para proceder a la remoción deben quedar claramente establecidas en la ley. Asimismo, consideramos importante reglamentar que los otros órganos, funcionarios o autoridades están obligados a colaborar con el inspector general cuando éste así lo solicite, fomentar la participación de la sociedad civil en este campo, la estructura, composición y funcionamiento del inspector general, y el carácter público de sus informes y recomendaciones.

La ley no restringe el nombramiento del inspector general a los profesionales del derecho, por lo tanto, cualquier persona puede aspirar a ocuparlo siempre y cuando tenga una trayectoria amplia en materia de derechos humanos y posea una alta solvencia moral y ética, además de una actitud firme $y$ una agresividad bien entendida para el adecuado cumplimiento de sus funciones que, al ser de vigilancia y control, nos llevan a un punto importante para una acertada selección: el o los candidatos no pueden ni deben surgir de la misma institución, puesto que entonces su objetividad no estaría garantizada. La persona que llegue a ocupar el cargo no debe tener vínculos con la cúpula de la Policía Nacional Civil ni con las instancias superiores de ésta, sino que debe proceder de fuera para que pueda hacer uso pleno de sus facultades, sin limitaciones de ningún tipo.

El nuevo inspector general debe crear un mecanismo accesible, ágil y permanente que facilite que los ciudadanos denuncien los casos que, en su opinión, lo ameriten. En esa línea, serfa saludable para la institución y para la población que las oficinas del inspector estuvieran ubicadas fuera de las instalaciones de la Polića Nacional Civil, porque ello ayudara a dar confianza a las víctimas de las violaciones cometidas por los policías. Este mecanismo deberfa contar con una red fluida de comunicación y coordinación entre los puestos policiales, los tribunales de justicia y las delegaciones departamentales de la Procuraduría para la Defensa de los Derechos Humanos. Por otro lado, el inspector general debería llevar un registro completo de las faltas y de sus responsables para garantizar la aplicación de las sanciones correspondientes $y$, además, para poder 
realizar una evaluación periódica y objetiva de los policías, en función de la profesionalización y del mejoramiento institucional.

Quizás sea el momento para responder a las interrogantes con las que iniciamos este comentario. Sin duda, entre las salvadoreñas y los salvadoreños que se encuentran dentro y fuera del país sí hay gente capaz. El problema es que, mientras no aparezca prueba en contrario, parece que no hay mucha voluntad política para apuntalar las instituciones claves en la construcción del presente y el futuro nacional o, en el mejor de los casos, no existe conciencia de su importancia. De cualquier forma, estas decisiones tienen que ser bien ponderadas para que no se sigan cometiendo los mimos errores del pasado u otros peores. Es necesario que en el proceso de selección de estos y otros funcionarios y funcionarias participe la población que, a final de cuentas, es la que resultará beneficiada o dañada según sea el caso. $Y$ es que ya no podemos ni debemos seguir equivocándonos, sobre todo en materia de derechos humanos. Si no se corrige el rumbo, nos surge una última interrogante: ¿cuánto durará lo poco que hasta ahora se ha avanzado?

IDHUCA

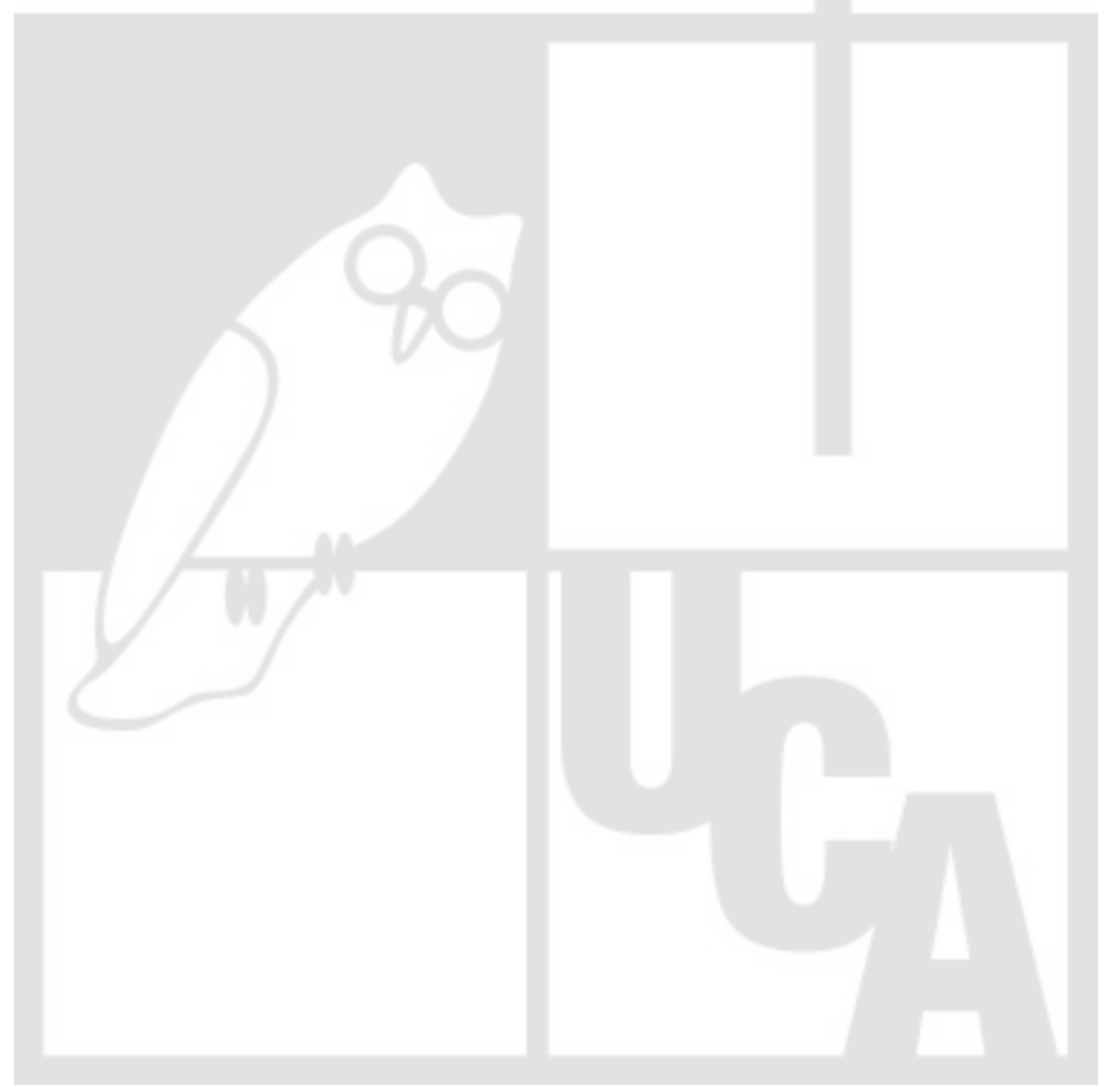

